\title{
МУЛЬТИПЛЕКСИРОВАНИЯ СВЕТОВОГО КОНТИНУУМА В ВОЛОКОННОМ ОТВЕТВИТЕЛЕ
}

\author{
Э.А. Захидов, И.И. Тажибаев, М.Х. Имомов, В.О. Кувондиков \\ ${ }^{1}$ Институт ионно-плазменных и лазерных технологии АН РУз, Ташкент, Узбекистан \\ ezakhidov@hotmail.com
}

\section{М.А. Захидова}

Национальный университет Узбекистана им. М. Улугбека, Ташкент, Узбекистан

\section{Ш.К. Нематов}

Ташкентский государственный технический университет им. И. Каримова, Узбекистан (Получена 29.04.2020)

\begin{abstract}
Мақ̆олада икки ўзакли нуртоладан бунда у нуртолани кичик (бир неча см) сохасида қุиздириш ва чўзиш орқ̨али ёруғлик тарқ̨атувчи ўзакларни яқุинлаштириш йўли билан хєосил қилинган нуртолали тармоқлагич таклиф қєилинган ва тажрибада амалга оширилган. Мазкур тармоклагичда нурланишнинг тор полосасини шакллантириш ёки 1 нм гача кенгликка эга ёруғлик континуумини спектрал фильтраш имкониятлари кўрсатиб берилган.

В данной статье предложен и экспериментально реализован волоконный ответвитель из двужильного волокна, формируемый путем сближения двух световедущих жил при сплавлении и растяжке небольшого (несколько см) участка такого волокна. Показана возможность спектральной фильтрации светового континуума в таком волоконном ответвителе с образованием узких полос излучения или формированием модулированного по спектру излучения шириной вплоть до 1 нм.

In the article, a fiber coupler based on twin-core fiber formed by the convergence of two light guiding cores by fusion and splicing of a small (several $\mathrm{cm}$ ) region of the fiber has been proposed and experimentally received. The possibility of spectral filtering of the light continuum in a such fiber coupler with the generation of narrow bands of radiation or the formation of spectrum-modulated radiation with a width of up to $1 \mathrm{~nm}$ is shown.
\end{abstract}

\section{I. ВВЕДЕНИЕ}

Возможности эффективного спектрального фильтрования, переключения и мультиплексирования света волн в волоконной петле связаны со степенью контролирования волноводных характеристик его ответвителя. В случае изготовления последнего широко используемым методом полировки оболочек и сближения световедущих жил двух параллельных волокон с последующим их склеиванием, возникают трудности, связанные с невозможностью online контроля указанных параметров непосредственно в процессе изготовления такого устройства и внесения соответствующей коррекции для достижения заданных их значений [1]. Это, в первую очередь, относится к таким волноводным параметрам ответвителя, как коэффициент ответвления, критически зависящий от расстояния между 
световедущими жилами волокон. Эти параметры жестко задаются расположением места полировки и толщиной удаляемого слоя оболочки волокна [2].

Волоконные интерферометры, изготовленные сплавным методом, в значительной степени свободны от таких недостатков, и их волноводные характеристики можно скорректировать прямо в процессе их изготовления (сплавления), слегка изменяя размеры или геометрию формируемого ответвителя, например, путем незначительной продольной растяжки сплавляемого участка волокон.

При использовании многожильного волокна для создания цельноволоконного интерферометра, в котором плечами интерферометра служат различные световедущие жилы одного и того же волокна, имеются дополнительные возможности для достижения высокой стабильности и точности настройки, так как в такой конструкции длины интерферирующих плеч автоматически являются одинаковыми. А расстояние между световедущими жилами можно выбрать еще в процессе изготовления такого волокна. Как показали наши исследования, в двужильном волокне методом сплавления и растяжения небольшого его участка можно сформировать направленный ответвитель, в котором можно эффективно управлять интенсивностями света в каждом из его световедущих жил. Примечательно, что на других участках такого волокна, если расстояние между жилами достаточно большое, свет может распространяться как две независимые волны, в том числе в нелинейном режиме. Последний, в частности, позволяет преобразовать вводимое лазерное излучение в световой континуум с определенными спектрально-кинетическими характеристиками. Рассмотрим особенности режима распространения света в двужильном волокне с произвольными волноводными характеристиками.

\section{IІ. ТУННЕЛЬНАЯ ВОЛНОВОДНАЯ СВЯЗЬ МЕЖДУ СВЕТОВЫМИ ВОЛНАМИ В ДВУЖИЛЬНОМ ВОЛОКНЕ}

Распространение света по двужильному волокну, при наличии волноводной связи между световедущими жилами, сопровождается взаимным обменом световой энергией между ними. Такое взаимодействие можно рассматривать как биение между симметричной и ассиметричной супермодами общей структуры, в данном случае двужильного волокна [1]. В рассматриваемом устройстве волноводную связь можно объяснить с помощью теории связанных мод. В этой теории две жилы волокна рассматриваются как единая структура из двух одномодовых волноводов, которая поддерживает симметричную (четную) и антисимметричную (нечетную) супермоды с разными постоянными распространения [2].

Для математического описания такой волноводной связи существуют два подхода. В первом коэффициент волноводной связи рассчитывается с использованием теории возмущений. Один волноводный канал рассматривается как слабое возмущение к другому, когда две одинаковые жилы волокна расположены довольно близко друг другу. Коэффициент связи рассчитывается с помощью интеграла пространственного перекрытия двух волноводных мод [3]. Используя соответствующие граничные условия, профиль мод волокна можно выразить через функцию Бесселя. В случае частичного перекрытия полей двух отдельных мод волокна, коэффициент волноводной связи между световедущими жилами волокна можно выразить как [4]: 


$$
k_{c}=\frac{\sqrt{2 \Delta}}{r} \frac{U^{2}}{V^{3}} \frac{K_{0}(W d / r)}{K_{1}(W)},
$$

где $U, V, W, \Delta$ - волноводные характеристики световедущих жил волокна в одномодовом режиме; $d$ - расстояние между центрами жил; $r$ - радиус оболочки волокна. $K_{0}$ - модифицированная функция Бесселя, $K_{1}-$ функция Бесселя второго рода. Величины $U, V, W, \Delta$ можно определить как:

$$
\begin{aligned}
& U=r \sqrt{k^{2} n_{1}^{2}-\beta^{2}}, \quad V=k \sqrt{\left(n_{1}^{2}-n_{2}^{2}\right)} r, \quad k=2 \pi / \lambda \\
& W=r \sqrt{\beta^{2}-k^{2} n_{2}^{2}}, \quad \Delta=\frac{\left(n_{1}^{2}-n_{2}^{2}\right)}{2 n_{1}^{2}}
\end{aligned}
$$

где $n_{1}$ - показатель преломления жил волокна, $n_{2}$ - показатель преломления его оболочки, $\beta$ - постоянная распространения света в жиле, $k$ - постоянная распространения света в свободном пространстве. В рассматриваемом случае считается, что световая волна полностью сосредоточена в пределах оболочки волокна, поэтому в уравнении (2) $\beta \approx k n_{1}, W \approx V$, а уравнение (1) можно выразить как:

$$
k_{c}=\frac{2}{r}\left(\frac{\sqrt{\Delta}}{2 \pi D}\right)^{1 / 2} \frac{U_{\infty}}{V^{5 / 2} e^{V(2 D-2)}},
$$

где $D=d^{\prime} / d, U_{\infty}=2.405, d^{\prime}$ - расстояние между центрами двух световедущих жил.

Уравнения (1) и (3) довольно точно описывают распространение света в условиях слабой связи между двумя жилами, однако, по мере увеличения силы связи, т.е. с приближением двух жил друг к другу, уравнение (3) становится все менее точным [5]. Полученное выражение достаточно затруднительно применить при прямом вычислении величины параметра $k_{c}$, так как для определения постоянных распространения необходимо оперировать сложными функциями Бесселя. На практике для направленного ответвителя, имеющего ограниченный интервал практически важных значений отношения $\bar{d}=l_{c} / r, k_{c}$ можно описать достаточно точно с помощью следующего эмпирического выражения [6]:

$$
k_{c}=\frac{\pi V}{2 k n_{1} r^{2}} \exp \left[-\left(c_{0}+c_{1} \bar{d}+c_{2} \bar{d}^{2}\right)\right],
$$

где постоянные $c_{0}, c_{1}, c_{2}$ зависят от параметра $V$ как $c_{0}=5.2789-3.663 V+0.3841 V^{2}$, $c_{1}=-0.7769+1.225 \mathrm{~V}-0.0152 \mathrm{~V}^{2}$ и $c_{2}=-0.0175-0.0064 \mathrm{~V}-0.0009 \mathrm{~V}^{2}$.

Представленный выше анализ наглядно показывает периодический характер физических свойств процесса взаимной перекачки света между световедущими жилами двужильного волокна с периодом $\pi / k_{c}$.

Выражение для коэффициента волноводной связи $k_{c}$, количественно характеризуя силу взаимосвязи двух жил, показывает, как свет, введенный в одну из жил волокна, перекачивается в другую при прохождении определенной длины. $k_{c}$ пропорционален разности постоянных распространения четной и нечетной супермод и, следовательно, зависит от геометрии и разности показателей преломления световедущих жил и оболочки. 
Для исследования распространения света в двужильном волокне и физических свойств периодической перекачки световых волн между двумя световедущими жилами были выбраны два образца таких волокон, параметры которых представлены в табл. 1.

Волокна были изготовлены методом «стрежни в трубке» [7] (сверление в стеклянной болванке из плавленного кварца $\left(\mathrm{SiO}_{2}\right)$ двух симметрично расположенных дырок и вставление в них стержней из плавленного кварца, легированных $\mathrm{GeO}_{2}$, с последующей вытяжкой из такого составного штабика волокна с необходимым диаметром).

Таблица 1. Волноводные параметры двужильных волокон.

\begin{tabular}{l|c|c}
\hline \multicolumn{1}{c|}{ Наименование параметра } & Волокно №1 & Волокно №2 \\
\hline Длина, м оболочки, мкм & 100 & 100 \\
Диаметр оболе & 125 & 125 \\
Диаметр сердцевины, мкм & 6 & 8 \\
Расстояние между сердцевинами, мкм & 24 & 32 \\
Длина волны отсечки, нм & 600 & 1200 \\
Показатель преломления световедущих жил на & 1.458 & \\
длине волны отсечки & & $3.2 \times 10^{-3}$ \\
Разность показателей преломления световедущих & $2.4 \times 10^{-3}$ & \\
$\begin{array}{l}\text { жил и оболочки } \\
\text { Концентрация } \mathrm{GeO}_{2} \text { в световедущих жилах }\end{array}$ & $2.3 \%$ & $3.1 \%$ \\
\hline
\end{tabular}

На рис. 1 показаны фотография поперечного сечения волокна №1 (a), снятая белым светом под микроскопом, и изображение дальнего поля света гелийнеонового лазера, прошедшего через короткий (15 см) отрезок такого волокна (б). Изображение поперечного сечения волокна довольно точно показывает геометрические параметры волокна, в то время как четкая, высококонтрастная интерференционная картина дальнего поля когерентного света с длиной волны 0.63 нм свидетельствует об одномодовом режиме его распространения в волокне № 1. Аналогичные свойства были выявлены и в волокне № 2 с применением света неодимого лазера с длиной волны 1.064 мкм $(6,2)$.

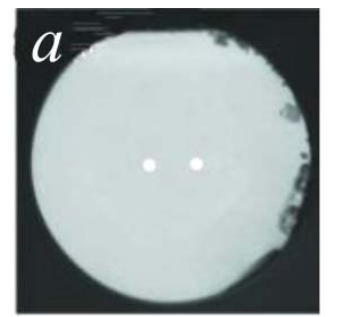

Волокно № 1

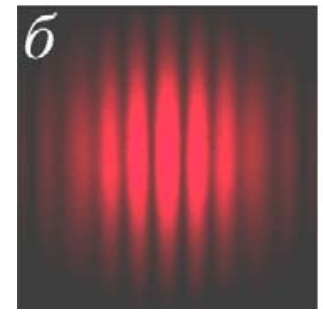

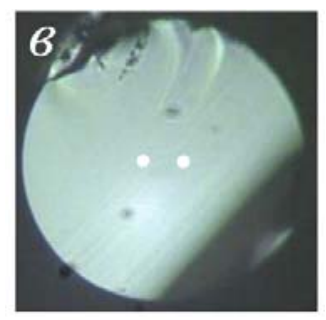

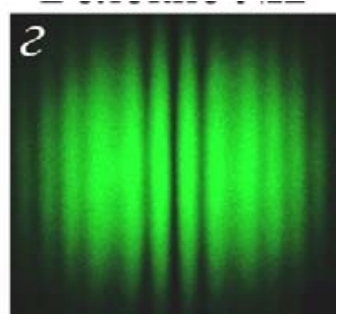

Волокно № 2

Рис. 1. Фотографии поперечного сечения и изображения дальнего поля света гелийнеонового/неодимого лазера на выходе волокна № $1(a, \sigma)$ и № $2(b, 2)$.

С учетом 10\%-ного превышения эффективного диаметра поля основной $\left(\mathrm{LP}_{01}\right)$ моды над диаметром световедущей жилы на длине ее волны отсечки, диаметр светового пятна в волокне № 1 составил 6.6 мкм, а в волокне № $2-8.8$ мкм. А из-за 
расползания светового поля этой же моды в область оболочки, диаметр светового пятна двукратно увеличивался на длине волны 1000 нм в волокне № 1 и на длине 1600 нм в волокне № 2. Такое расползание света в область оболочки и приближение к области расположения другой световедущей жилы, естественно, резко увеличивает волноводную связь между жилами (рис. 2).

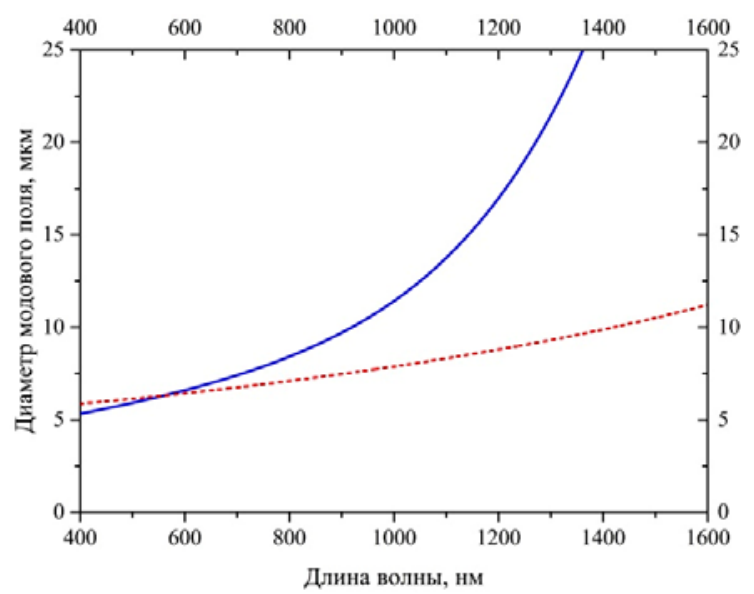

Рис. 2. Зависимости диаметров полей мод в волокнах № 1 (сплошная линия) и № 2 (штриховая линия) от длины волны излучения.

Так как коэффициент связи $k_{c}$, кроме волноводных параметров, зависит также от длины волны света при прохождении светового континуума через двужильное волокно, на его выходе в каждой жиле можно получить свет соответствующего спектра, зависящего от волноводных характеристик волокна. Поэтому, подбирая необходимые значения последних, можно получить свет с заданными спектральными свойствами. В наших экспериментах в таких условиях был изготовлен эффективный ответвитель с сильно увеличенным $k_{c}$ на небольшом, $\sim 1 \mathrm{~cm}$, участке волокна.

Причем, ответвитель был сформирован на конце отрезка двужильного волокна длиной в несколько метров, что позволило реализовать цельноволоконную конструкцию, в которой длинный начальный участок волокна служил генератором светового континуума при накачке мощным неодимовым лазером с $\lambda_{\mathrm{H}}=0.532 \mathrm{Hм}$ (волокно № 1) или $\lambda_{\text {н }}=1.064$ мкм (волокно № 2) [9], а направленный ответвитель в конце этого же волокна - спектральным фильтром, выделяющим определенную часть генерированного светового континуума. На рис. 3 показана схема такого цельноволоконного устройства

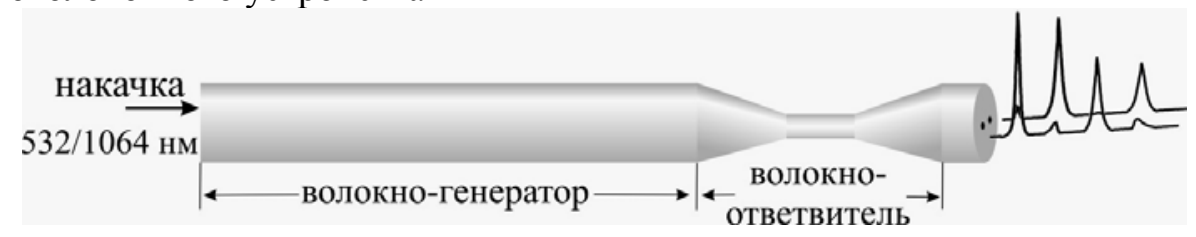

Рис. 3. Схема цельноволоконного генератора, преобразователя светового континуума из двужильного волокна. В конце двужильного волокна длиной в несколько метров сформирован направленный ответвитель с заданными значениями волноводной связи между световедущими жилами. 


\section{ІІІ. СПЕКТРАЛЬНАЯ ФИЛЬТРАЦИЯ СВЕТОВОГО КОНТИНУУМА В ДВУЖИЛЬНОМ ВОЛОКНЕ}

Сужение диаметра волокна при его смягчении и продольном растяжении из-за сил поверхностного натяжения приводит к уменьшению диаметра и световедущих жил с соответствующим увеличением диаметра пятна света в них, а также к взаимному сближению жил. Используя такой метод, в волокне № 1 был сформирован направленный ответвитель для спектральной фильтрации светового континуума в видимой области. На рис. 4а показаны рассчитанные спектральные зависимости коэффициента волноводной связи, $k_{c}$, в двужильном волокне № 1 до (штриховая линия) и после (сплошная линия) сужения его диаметра в два раза. Как видно из рисунка, в волокне № 1 волноводная связь очень слабая (максимальное значение $k_{c}$ во всем спектре континуума не превышает $0.3 \mathrm{~m}^{-1}$ ) и становится заметной только на длинах волн $\lambda>550$ нм.

Но двукратное уменьшение диаметра волокна (как оболочки, так и жил) и соответственно расстояния между жилами, увеличивает $k_{c}$ на три порядка, показывая его экспоненциальную зависимость от $\lambda$. Значения $k_{c}$, превышающие единицы $\mathrm{cm}^{-1}$ в большей части видимого спектра, показывают, что для эффективной взаимной перекачки света между световедущими жилами достаточно длины ответвителя $\leq 1$ см.
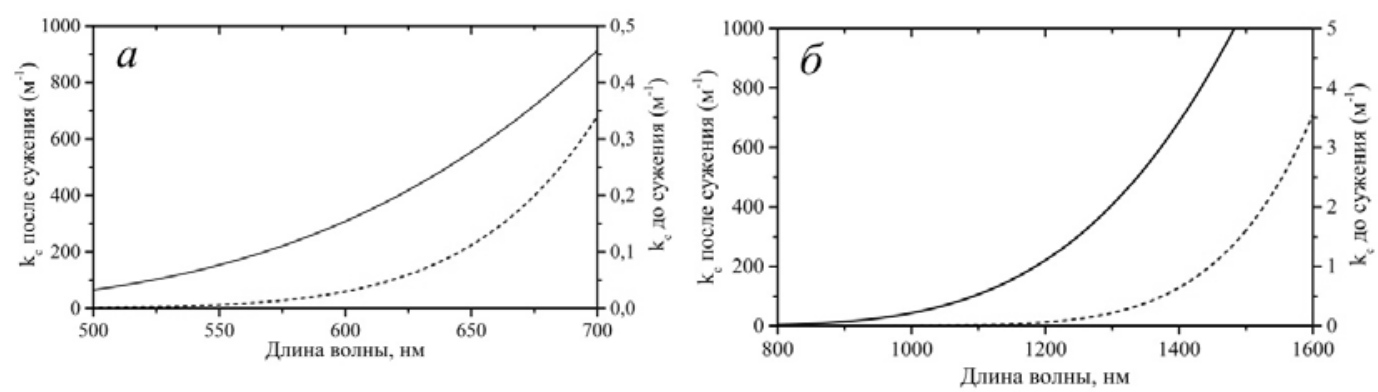

Рис. 4. Спектральные зависимости коэффициента волноводной связи, $k_{c}$, в двужильном волокне № 1 (a) и № 2 (б) до (штриховая линия) и после (сплошная линия) сужения его диаметра в два раза.

В волокне № 2, спроектированном для работы в ближней ИК области спектра, если его сравнивать с волокном № 1, при почти двойном превышении рабочих длин волн, расстояние между жилами больше только на 33\%. Это обстоятельство обуславливает несколько более сильную волноводную связь между жилами в этом волокне. На рис. $4 б$ показаны спектральные зависимости коэффициента связи, $k_{c}$, в волокне № 2 до (штриховая линия) и после (сплошная кривая) сужения диаметра в два раза. Как видно из рисунка, в свободном (не суженном) отрезке этого волокна, на длинах волн менее 1.1 мкм $k_{c}$ практически равен 0 . Но на более длинных волнах он резко увеличивается, доходя до $\sim 3.5 \mathrm{~m}^{-1}$ на длине волны 1.6 мкм. Однако при двукратном сужении диаметра волокна $k_{c}$ увеличивается на порядки и в спектральной области $\lambda>1.1$ нм превышает $100 \mathrm{~m}^{-1}$. Последнее означает, что свет с длиной волны более 1.1 мкм в таком ответвителе претерпевает полную перекачку из одной жилы в другую на расстоянии менее 1 см [9]. 
В экспериментах генерация светового континуума в видимой области спектра и его спектральная фильтрация в двужильном волокне осуществлялись следующим образом. В одну из световедущих жил волокна № 1 длиной 3 м вводился свет накачки в виде излучения лазера с $\lambda_{H}=0.532$ мкм и $P_{u}=38$ кВт, когда наблюдалась генерация континуума, спектр которого показан на рис. 5а.

При прохождении ответвителя, образованного в конце указанного волокнагенератора путем сужения его диаметра в два раза, часть светового континуума с определенным спектром перекачивается в другую жилу (спектральная фильтрация). На рис. 5а показаны спектры света, прошедшего через ответвитель в двух случаях, при значениях его длины $L_{c} 31$ и 38 мм.
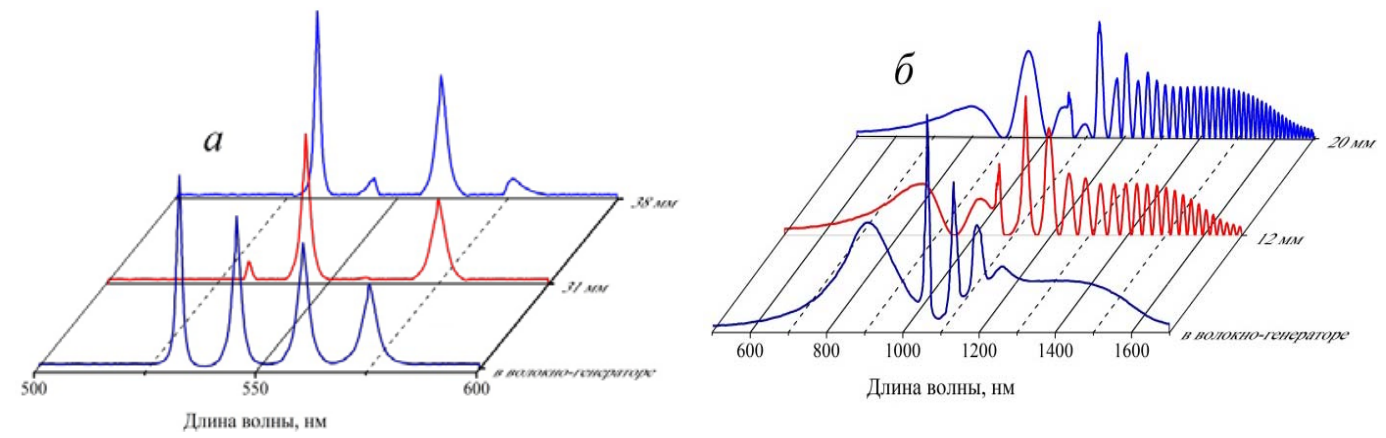

Рис. 5. Спектры широкополосного света, полученного в двужильном волокне: $a-$ волокно № 1 при накачке с $\lambda_{t}=0.532$ мкм) до и после прохождения ответвителя с длинами 31 и 38 мм, $\sigma$ - волокно № 2 при накачке с $\lambda_{н}=1.064$ мкм до и после прохождения ответвителя с длинами 12 и 20 мм.

На рис. $5 б$ показан спектр светового континуума, полученного при накачке лазерным излучением с $\lambda_{H}=1.064$ мкм и $P_{u}=30$ кВт на отрезке волокна № 2 длиной 5 м. Спектр такого континуума охватывает очень широкую часть ближней ИК области, простирающейся от 700 до 1700 нм, включая длины волн, на которых наблюдаются минимальные значения оптических потерь (при 1.55 мкм) и дисперсии (при 1.3 мкм) в волокнах на основе плавленого кварца. Таким образом, свет с управляемым спектром в ближней ИК области, полученный с помощью подобного устройства, может иметь большие перспективы для применения в тестировании систем оптической связи и передачи информации.

В рассматриваемом случае, также как и в волокне № 1, даже при небольших длинах ответвления можно добиться сильной спектральной фильтрации светового континуума и выделить заданную часть света. Причем ширина выделяемой одиночной полосы может быть довольно узкой [10].

Как видно из рис. 5, при генерации и спектральной фильтрации светового континуума в двужильном волокне в ближней ИК области спектра, в области минимальных потерь и дисперсии (на длинах волн 1.2-1.6 мкм) можно получить довольно ровные по интенсивности и периодически расположенные полосы света, ширины которых определяются силой волноводной связи между жилами волокна. Наличие такой упорядоченной последовательности узких полос света в практически важной для оптической связи области спектра подсказывает, что на основе таких структур можно создать высокоэффективные, но вместе с тем 
простые в своем функционировании, световые источники для многоканальных систем оптической связи с частотным уплотнением (WDM). Как известно, для обеспечения сверхвысоких скоростей систем оптической связи за счет частотного уплотнения спектральная ширина источника света в уплотняемом канале должна быть менее 10 нм. Рассмотрим возможности спектральной фильтрации узких световых полос в волокнах № 1 и № 2 соответственно для видимой и ближней ИК областей спектра.

В табл. 2 показаны рассчитанные значения промежутков между световыми полосами на разных длинах волн при различных значениях волноводной связи (длины ответвления). Как видно из сравнения значений промежутков между выделенными полосами, в случае спектральной фильтрации светового континуума в волокнах № 1 и № 2 при различных длинах ответвителя рассмотренным способом можно создать источники для использования в частотном уплотнении со спектральной шириной вплоть до 10 нм в видимой области и $\sim 1$ нм в ближней ИК области спектра.

Таблица 2. Рассчитанные значения промежутков между спектральными полосами при спектральной фильтрации света в двужильном волокне.

\begin{tabular}{c|c|c|c|c|c|c|c|c}
\hline \multirow{2}{*}{$L_{c}$} & \multirow{2}{*}{ Волокно } & \multicolumn{7}{|c}{ Расстояние между световыми полосами } \\
\cline { 3 - 9 } & & $\Delta \lambda_{1}$ & $\Delta \lambda_{2}$ & $\Delta \lambda_{3}$ & $\Delta \lambda_{4}$ & $\Delta \lambda_{5}$ & $\Delta \lambda_{6}$ & $\Delta \lambda_{n}$ \\
\hline 31 мм & № 1 & $22.7 \mathrm{HM}$ & $17.8 \mathrm{HM}$ & $14.9 \mathrm{HM}$ & $12.7 \mathrm{HM}$ & $11.3 \mathrm{pm}$ & $10 \mathrm{HM}$ & - \\
$38 \mathrm{MM}$ & № 1 & $24.4 \mathrm{HM}$ & $19.4 \mathrm{HM}$ & $15.5 \mathrm{HM}$ & $13.4 \mathrm{HM}$ & $12.1 \mathrm{HM}$ & $10 \mathrm{HM}$ & - \\
$12 \mathrm{MM}$ & № 2 & $75.6 \mathrm{HM}$ & $52.3 \mathrm{HM}$ & $40.8 \mathrm{HM}$ & $34.7 \mathrm{HM}$ & $27.2 \mathrm{HM}$ & $25 \mathrm{HM}$ & $0.8 \mathrm{HM}$ \\
$20 \mathrm{Mm}$ & № 2 & $67.5 \mathrm{HM}$ & $44.9 \mathrm{HM}$ & $35.3 \mathrm{HM}$ & $28.6 \mathrm{HM}$ & $25.4 \mathrm{HM}$ & $21 \mathrm{HM}$ & $0.8 \mathrm{HM}$ \\
\hline
\end{tabular}

\section{IV. ЗАКЛЮЧЕНИЕ}

В работе изучено формирование светового континуума в видимой и ближней ИК областях спектра в волоконном устройстве, состоящем из одномодового двужильного волокна и направленного разветвителя, образованного на его выходном конце методами сплавления и вытяжки. В цельноволоконной конструкции «волокно-генератор»+«волокно-ответвитель» из волокна, разработанного для видимой и ближней ИК областей, при подборе коэффициента связи и длины ответвителя путем накачки лазерным излучением с $\lambda_{p}=0.532 / 1.064$ мкм получен свет с заданными спектральными характеристиками в спектральной области 500-600/700-1700 нм. Такой источник, с учетом возможности генерации в нем световых импульсов пико- и фемтосекундных длительностей, имеет большие перспективы для применения в решении различных задач сверхбыстрой лазерной спектроскопии. Широкополосное излучение с таким управляемым спектром, полученное с помощью подобного устройства, может иметь большие перспективы для применения в тестировании систем оптической связи и передачи информации.

Настоящая работа выполнена при поддержке проекта ОТ-Ф2-05 в рамках программы фундаментальных исследований Республики Узбекистан.

\section{ЛИТЕРАТУРА}

1. G. Agrawal. Applications of Nonlinear Fiber Optics (USA, Academic Press, 2010).

2. E.G. Neumann. Single-Mode Fibers: Fundamentals (Amsterdam, Springer, 2013). 
3. M.J.F. Digonnet, H.J. Shaw, IEEE Transactions on Microwave Theory and Techniques 30, № 4, 592-600 (1982).

4. B. Pal, Fiber and Integrated Optics 22, № 2, 97-117 (2003).

5. A.W. Snyder, J. Love. Optical Waveguide Theory (Berlin, Springer, 2012).

6. Э.А. Захидов, А.М. Коххаров, Ф.М. Миртаджиев, Ш.К. Нематов, И.И. Таджибаев, С.А. Убайдуллаев, Узбек. физич. журн. 18, № 1, 20-28 (2016).

7. E.A. Zakhidov et al., Turkish. J. of Physics 38, № 1, 64-72 (2014).

8. K. Schuster et al., Advanced Optical Technologies 3, № 4, 447-468 (2014).

9. E.A. Zakhidov, Sh.Q. Nematov, I.I. Tadjibaev, Journal of Lightwave Technology 34, No 13, 3126-3130 (2016).

10. C. Schubert et al., Journal of Lightwave Technology 20, № 4, 618-624 (2002). 